\title{
Biological rejuvenation of iron oxides in bioturbated marine sediments
}

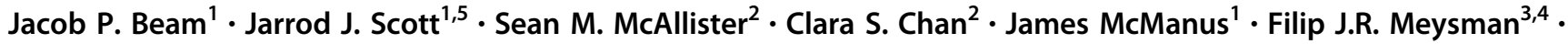 \\ David Emerson ${ }^{1}$
}

Received: 20 April 2017 / Revised: 22 November 2017 / Accepted: 29 November 2017 / Published online: 17 January 2018

(C) International Society for Microbial Ecology 2018

\begin{abstract}
The biogeochemical cycle of iron is intricately linked to numerous element cycles. Although biological processes that catalyze the reductive side of the iron cycle are established, little is known about microbial oxidative processes on iron cycling in sedimentary environments-resulting in the formation of iron oxides. Here we show that a potential source of sedimentary iron oxides originates from the metabolic activity of iron-oxidizing bacteria from the class Zetaproteobacteria, presumably enhanced by burrowing animals in coastal sediments. Zetaproteobacteria were estimated to be a global total of $10^{26}$ cells in coastal, bioturbated sediments, and predicted to annually produce $8 \times 10^{15} \mathrm{~g}$ of Fe in sedimentary iron oxides55 times larger than the annual flux of iron oxides deposited by rivers. These data suggest that iron-oxidizing Zetaproteobacteria are keystone organisms in marine sedimentary environments-despite their low numerical abundanceyet exert a disproportionate impact via the rejuvenation of iron oxides.
\end{abstract}

\section{Main}

Large amounts of iron oxides are released by continental weathering $\left(\sim 1.4 \times 10^{14} \mathrm{~g}\right.$ per year $)$ that are transported by rivers, and deposited in coastal and continental shelf sediments ([1] and references therein). Poorly crystalline, highly reactive iron oxides (i.e., ferrihydrite and lepidocrocite) comprise a major component of fine-grained riverine sediments [1] that are rapidly transformed between reduced and

Electronic supplementary material The online version of this article (https://doi.org/10.1038/s41396-017-0032-6) contains supplementary material, which is available to authorized users.

Jacob P. Beam

jbeam@bigelow.org

1 Bigelow Laboratory for Ocean Sciences, East Boothbay, ME 04544, USA

2 Department of Geological Sciences, University of Delaware, Newark, DE 19716, USA

3 Department of Biology, University of Antwerp, Universiteitsplein 1, 2610 Wilrijk, Belgium

4 Department of Biotechnology, Technical University of Delft, Van der Maasweg 9, 2629 HZ Delft, The Netherlands

5 Present address: Smithsonian Tropical Research Institute, Apartado Postal 0843-03092, Panamá, Republic of Panama oxidized phases in marine sediments upon deposition by numerous chemical and biological redox reactions. The biological and chemical reduction of iron oxides is estimated to be 100-300 times faster than riverine input [2]. These high rates of reduction would quickly exhaust the sedimentary pool of iron oxides and thus require a rapid reoxidation of ferrous iron $[\mathrm{Fe}(\mathrm{II})]$ in sediments to produce fresh, amorphous, authigenic iron oxides [1]. Conventionally, the aerobic re-oxidation of $\mathrm{Fe}(\mathrm{II})$ in pore waters is primarily thought to be a chemical process, especially in areas with significant sediment mixing and irrigation by animals-bioturbation and bioirrigation-where oxygen is transported deep into sediments by burrow flushing [1, 3, 4]. Although sedimentary chemical oxidation of iron is important under saturated oxygen conditions at neutral $\mathrm{pH}$ [4], bioirrigated sediments contain microenvironments that have oxygen levels well below air saturation [5, 6] where the biological contribution to iron oxidation is quantitatively more significant [7]. Collectively, these findings suggest that biology may contribute significantly to aerobic iron oxidation in marine sediments where bioturbation by macrofauna stimulates iron cycling [8, 9].

The Zetaproteobacteria represent a class of ironoxidizing bacteria (FeOB) that are exclusively found in marine and saline-influenced environments that contain high ferrous iron [Fe(II)] concentrations [10-13]. Coastal 
marine sediments can have pore water Fe(II) concentrations ranging from below detection up to $2000 \mu \mathrm{mol} \mathrm{L}{ }^{-1}$ that are capable of supporting lithoautotrophic populations of Zetaproteobacteria [14]. Recent studies have identified Zetaproteobacteria in surface openings of benthic macrofauna in the Mediterranean Sea [15], worm burrows in submarine groundwater discharge into sands in Delaware [16], coastal sediments in Denmark [17], and Baltic and North Sea sediments [18]. Zetaproteobacteria appeared to be the dominant iron-oxidizing microorganisms in coastal sediments of Denmark demonstrated by microaerobic and anaerobic culture-dependent techniques [17]. Moreover, quantitative PCR with Zetaproteobacteria-specific 16S rRNA gene primers revealed abundances of $\sim 10^{6}$ cells per gram sediment [17]. These recent studies suggest that Zetaproteobacteria may play a significant role in iron oxidation in marine sediments - a quantitative estimate of their abundance and distribution is necessary to determine their potential biogeochemical role on a global scale.

We analyzed coastal sediment microbial communities to determine the presence and abundance of Zetaproteobacteria from geographically diverse sites $(n=90$; Supplementary Table 1) utilizing 16S rRNA gene sequencing. Aerobic iron oxidation appears ubiquitous in the Zetaproteobacteria $[12,19,20]$, thus $16 \mathrm{~S}$ rRNA gene homology can be used to infer this specific metabolism. We also enriched for environmentally relevant $\mathrm{FeOB}$ from coastal sediments in Maine, which provided further metabolic evidence of the importance of iron oxidation in marine sediments. A metaanalysis of $16 \mathrm{~S}$ rRNA gene studies revealed the potential importance of Zetaproteobacteria in the global sedimentary iron biogeochemical cycle.

We identified Zetaproteobacteria in $60 \%$ of our samples from coastal sediments (Supplementary Table S1; Supplementary Figure S1). The median relative abundance of Zetaproteobacteria was $1.1 \%$ of the total microbial community (range $=0.04-15 \%$ ) in worm (e.g., polychaete) burrows in coastal sediments (Fig. 1a). Zetaproteobacteria were 10 times less abundant in bulk sediments (Fig. 1a) with a median of $0 \%$ (range $=0.0-1.0 \%$ ), and were significantly different from worm burrows $(p$-value $=9.2 \times 10$ ${ }^{-7}$, Wilcoxon test). The large variability $(0.04-15 \%)$ and non-normal distribution of Zetaproteobacteria relative abundance in worm burrows (Supplementary Materials and Methods) was most likely a combination of differences in burrow ventilation rates and efficiencies [5, 6], differences in sediment physicochemical conditions (Supplementary Table S1), and sampling bias (for example, residual sediment on burrow walls).

Zetaproteobacteria were not the only iron-oxidizing taxa that were positively correlated with the worm burrow environment (Supplementary Figure S1). Freshwater ironoxidizing Gallionella spp. were also found at some sites that had lower salinity values, potentially indicating
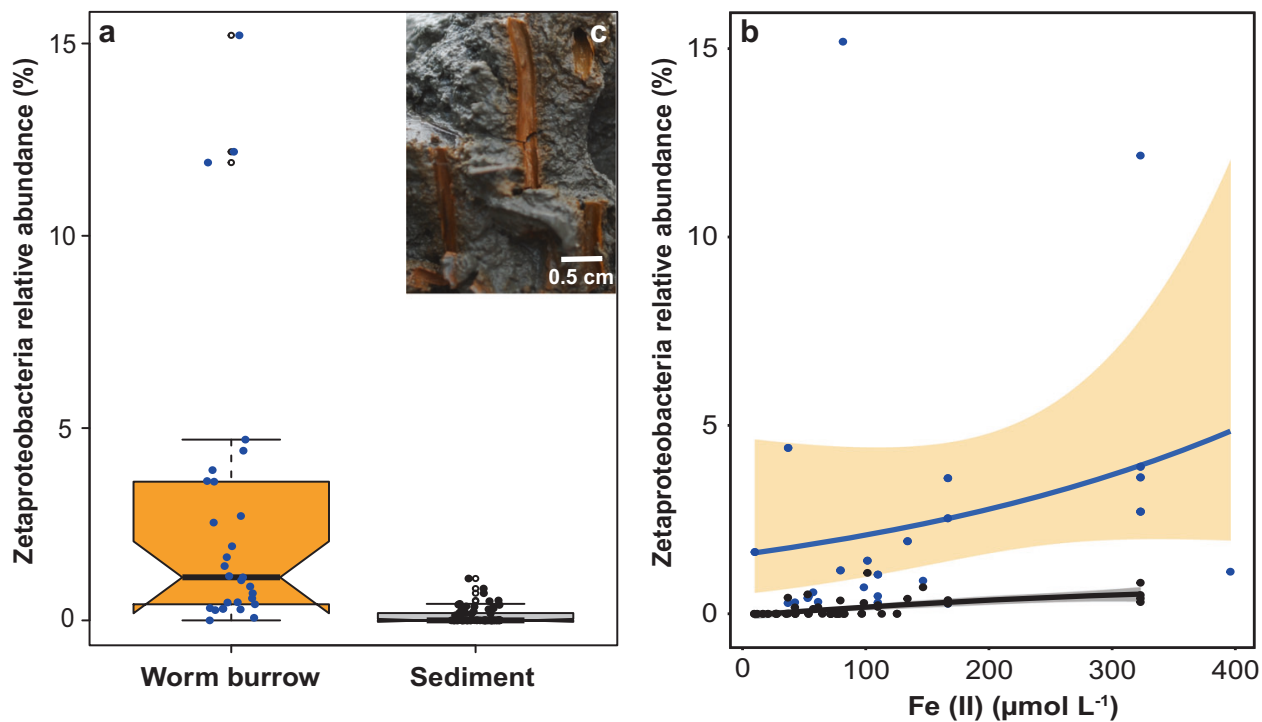

Fig. 1 Boxplots of the relative abundance of Zetaproteobacteria $\mathbf{a}$ in iron oxide-lined worm burrow walls $(n=29)$ and surrounding sediments $(n=$ $61)$. Notches are representative of $95 \%$ confidence interval and the medians (solid black lines) between worm burrows and sediments (1.1\% and $0 \%$, respectively) are statistically different ( $p$-value $=9.2 \times 10^{-7}$, Wilcoxon test). Filled circles represent individual data points and open circles indicate outliers. Zetaproteobacteria relative abundance $(\%)$ as a function of pore water ferrous iron [Fe(II)] concentration $\left(\mu \mathrm{mol} \mathrm{L} \mathrm{L}^{-1}\right) \mathbf{b}$ from worm burrows (blue circles, fitted blue line, orange fill $=95 \%$ confidence interval) and sediments (black circles, fitted black line, gray fill $=95 \%$ confidence interval; see Methods for details on line fits). Characteristic iron oxide-lined worm burrow walls (c) from "The Eddy", Sheepscot River, Maine, USA (image from 27 August 2015). Burrow walls are likely created by the polychaete, Nereis diversicolor, or hemichordate, Saccoglossus kowalevskii, which are both common to these intertidal sediments in Maine 
significant freshwater mixing (Supplementary Figure S1; Supplementary Table S1). Similar findings have been reported from brackish estuaries in Maine [11] and from coastal sediments in the North and Baltic Seas [18]; there is no definitive evidence of iron-oxidizing members of $\mathrm{Gal}$ lionella in marine environments. Although there may be other microorganisms capable of aerobic iron oxidation in marine sediments [21], they could not be solely determined by $16 \mathrm{~S}$ rRNA gene sequences.

Bioirrigation by benthic animals increases the extent of oxidative processes in these sediments, thus biological iron oxidation can occur at greater depths (10 s of centimeters) than typical oxygen penetration of a few millimeters into coastal surface sediments [22]. The abundance of Zetaproteobacteria at the burrow walls correlated with the concentration of pore water ferrous iron [Fe(II)] (Fig. 1b), which is their main energy source, and could result in the production of solid-phase iron oxides around worm burrows (Fig. 1c). Quantitatively, highly reactive, iron oxidesoperationally extractable by sodium dithionite [23] — were three times higher at burrow walls compared to the surrounding sediment, and accounted for $20-40 \%$ of the iron oxides with depth (Supplementary Figure S2 and S3). These freshly produced iron oxides are important substrates for iron-reducing microorganisms that release $\mathrm{Fe}(\mathrm{II})$ into pore waters, thus creating a tight cycling of iron between reduced and oxidized phases near burrow walls [8]. Eventually, dissolved iron $(\mathrm{dFe})$ is transported out of the sediment, supplying a critical nutrient for phytoplankton primary production in coastal and continental shelf waters [24]. These iron oxides play a key role in various sedimentary processes: mineralization of organic matter in marine sediments by iron-reducing bacteria [4]; substrates for early diagenesis of pyrite [25]; enhancement of organic carbon burial [26]; and inhibition of pore water hydrogen sulfide, preventing euxinic conditions detrimental to benthic animals [5, 27].

The relative abundance of Zetaproteobacteria in worm burrows resembles the $\mathrm{Fe}(\mathrm{II})$ concentration profile (Supplementary Figure S4), and both were at their maximum values around $2-3 \mathrm{~cm}$. The high Fe(II) $(\sim 40-140 \mu \mathrm{M})$ and low oxygen $(\sim 20-60 \mu \mathrm{M})$ conditions present in bioturbated sediment pore waters (Supplementary Figure S3) are suitable habitats for microaerophilic Zetaproteobacteria to thrive [7]. The relative abundance of Zetaproteobacteria decreased with depth in both burrows and sediments (Supplementary Fig. S4), possibly due to the decrease in Fe (II) with depth and increase in hydrogen sulfide production by sulfate-reducing bacteria [28]. Although there is oxygen in these sediments at depth (Supplementary Figure S4), hydrogen sulfide may inhibit oxygen respiration in Zetaproteobacteria under these conditions. The formation of iron sulfide minerals with increasing depth by biogenic sulfide may also compete with Zetaproteobacteria for access to $\mathrm{Fe}$ (II). Under these iron-rich settings in bioturbated sediments $(1-10 \mathrm{~cm}$ deep), biotic rates of $\mathrm{Fe}(\mathrm{II})$ oxidation could exceed abiotic chemical oxidation [7].

Two Zetaproteobacteria operational taxonomic units (herein, referred to as ZetaOTUs) dominated the Zetaproteobacterial diversity in worm burrows (Supplementary Table S2). The dominant ZetaOTU across all samples was ZetaOTU14, which comprised $32 \%$ of all ZetaOTUs (Supplementary Table S2), and is represented by four single-cell amplified genomes (SAGs) from diffuse flow vent systems [12, 13, 19]. We isolated the first member of ZetaOTU14 (strain CSS-1) from iron oxide surface flocculent in a laboratory bioturbation microcosm (Supplementary Figure S5). This strain grew best under low oxygen $\left(\sim 60 \mu \mathrm{M} \mathrm{O}_{2}\right)$ and high $\mathrm{Fe}(\mathrm{II})$ concentrations similar to those measured from sediment pore waters (Supplementary Figure S3). Strain CSS-1 produced fine stalks ( $<1 \mu$ m thick) encrusted with poorly crystalline iron oxides under laboratory conditions (Supplementary Figure S4). These iron oxides are similar to those produced by other Zetaproteobacteria [29], as well as in naturally occurring iron mats associated with diffuse flow hydrothermal vents, which are highly reactive [30]. Single-cell genomes from ZetaOTU14 representatives contained genes essential for growth on iron and low oxygen conditions (Supplementary Table S2). The second most abundant OTU was ZetaOTU9 (22\%) and is represented by two cultured isolates (Ghiorsea bivora strains TAG-1 and SV108) [31], as well as five SAGs from deep-sea vents (Supplementary Table S2). ZetaOTU9 isolates also had genes necessary for growth on iron and low oxygen (Supplementary Table S2), and have also been shown to grow via hydrogen oxidation, which may explain the ubiquity of this OTU in sediments and other environments (see below). There was no clear distribution of ZetaOTUs 14 and 9 with respect to depth (Supplementary Figure S4) in worm burrows and sediments, although it is likely that they are adapted for specific $\mathrm{Fe}(\mathrm{II})$ and $\mathrm{O}_{2}$ concentrations [19].

We searched for Zetaproteobacterial 16S rRNA gene sequences in marine sediment data sets (Supplementary Table S3), and identified them in numerous sediments on a global scale (Fig. 2). We found a pattern consistent with our samples-ZetaOTUs 14 and 9 were present and generally the most abundant ZetaOTUs in coastal and shelf sediments (Fig. 2). Zetaproteobacteria relative abundance was not found to exceed $1 \%$ in other studies, as microenvironments were not considered, which are abundant in bioturbated sediments [5, 6]. Accordingly, we hypothesize that when the abundance of Zetaproteobacteria exceeds $\sim 0.5 \%$ in sediments, there is active growth and iron oxidation associated with bioturbating and bioirrigating animals. 


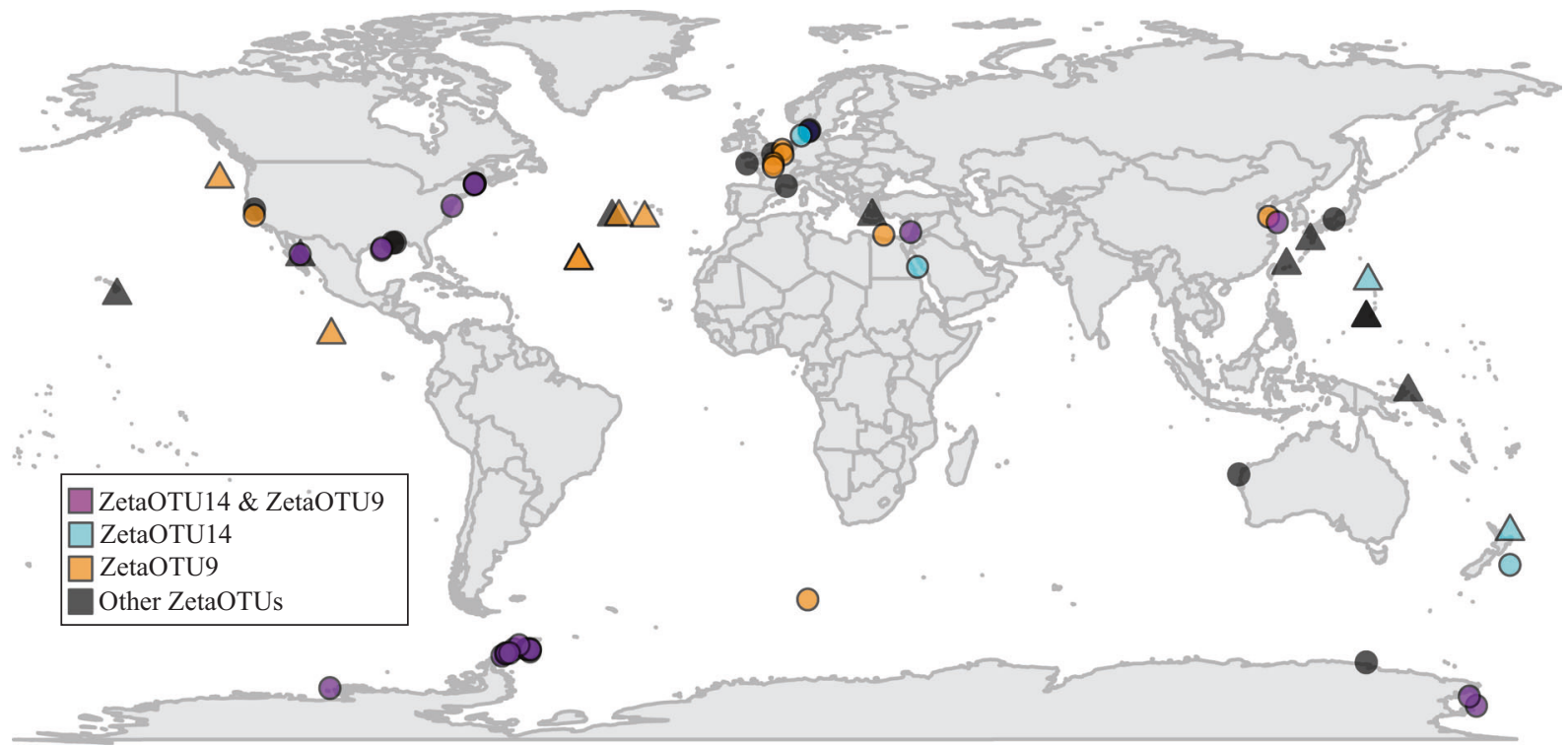

Fig. 2 Global distribution of Zetaproteobacteria in marine sediments (circles) and non-sediment sites (triangles) such as hydrothermal vents. The relative abundance of Zetaproteobacteria in sediments from other $16 \mathrm{~S}$ rRNA gene studies was never above $1 \%$ and was typically within

We can estimate the potential contribution of ironoxidizing Zetaproteobacteria to the production of iron oxides in the upper $10 \mathrm{~cm}$ of bioturbated shelf sediments [32] utilizing these data. Prior research has shown good correlation between relative abundance measurements from quantitative PCR and high-throughput 16S rRNA gene amplicon sequencing from sediments [16]. The total abundance of cells in worm burrows and sediments $(10 \mathrm{~cm}$ depth) was estimated to a median of $2.0 \times 10^{9}$ (range $=$ $\left.8.0 \times 10^{6}-7.2 \times 10^{9}\right) \quad$ and $4.1 \times 10^{8} \quad$ (range $=1.2 \times$ $10^{7}-5.4 \times 10^{9}$ ) cells per gram sediment, respectively (Supplementary Figure S6). Coastal environments comprise 7\% of the total area of ocean sediments and harbor $33 \%$ of the total sedimentary microbial biomass [33], which contain $2.1 \times 10^{19} \mathrm{~cm}^{3}$ of sediment $([34,35]$. From our estimations, this would equate to median values of $4.2 \times 10^{28}$ and $8.2 \times$ $10^{27}$ total cells in worm burrows and sediments, respectively, which are in agreement with other estimates based on direct cell counts $[6,33]$. Zetaproteobacteria relative abundance ranged from 0.04 to $15 \%$ (median $=1.1 \%$ ) of the total cells in coastal bioturbated sediments (Fig. 1a), and this yields a median value of $1.1 \times 10^{26}$ total cells (range $=$ $3.8 \times 10^{24}-1.4 \times 10^{27}$ cells). The global Zetaproteobacteria abundance estimate was then used with recent iron oxide production rate measurements from diffuse flow vents $\left(\sim 1.3 \times 10^{-16} \mathrm{~mol} \mathrm{Fe}\right.$ per cell per h) [37], which could result in the production of $\sim 8 \mathrm{Pg}$ of $\mathrm{Fe}$ in iron oxides per year (range $=0.1-70 \mathrm{Pg}$ Fe per year; see Supplemental Materials and Methods for more details on calculations). Recent twodimensional, sub-millimeter $\mathrm{Fe}(\mathrm{II})$ measurements in the range measured from bulk marine sediments from Maine. Sequences are from numerous studies (Supplementary Table S3) that include Sanger, 454, and Illumina sequencing technologies

bioturbated sediments revealed extensive $\mathrm{Fe}(\mathrm{II})$ oxidation occurring within the immediate vicinity of worm burrows and a rapid re-oxidation rate of $3.8 \pm 1.4 \mathrm{mmol} \mathrm{Fe} \mathrm{per} \mathrm{m}^{2}$ per day [8]. These chemical rate measurements combined with an estimate of the global volume of bioturbated coastal sediments $10 \mathrm{~cm}$ deep $\left(\sim 2.1 \times 10^{13} \mathrm{~m}^{3}\right)$ [34] would equate to an annual production of $1.6 \pm 1.1 \mathrm{Pg}$ of $\mathrm{Fe}$ in iron oxides. These two independent estimations of iron oxide production rates are well within the range of one another by less than a factor of 5. There are many assumptions and unknowns in these estimates such as the spatiotemporal heterogeneity that likely exist in these sedimentary environments, but do provide a first glimpse of the possible contribution of ironoxidizing Zetaproteobacteria on iron oxide rejuvenation in coastal sediments. Based on these estimates, the annual biological oxidation of iron in sediments-forming iron oxides-could exceed the annual flux of iron oxides from rivers to coastal sediments [38] by up to a factor of 55 .

Zetaproteobacteria may exert a profound impact on global sedimentary biogeochemistry via the production of biogenic, highly reactive iron oxides despite their low estimated global abundance $(\sim 0.11 \%)$-effectively functioning as keystone microorganisms (for example, [39]) in bioturbated coastal sediments. Zetaproteobacteria could contribute significantly to the rapid rates of $\mathrm{Fe}$ (II) reoxidation measured and observed in coastal sediments [8]. Climate change outcomes such as coastal hypoxia may have positive or negative impacts on the sedimentary iron biogeochemical cycle-either stimulating microaerobic bacterial iron oxidation resulting in an increase in iron oxide 
production, thus enhancing $\mathrm{dFe}$ release or inhibiting oxidation by the increase in hydrogen sulfide production, precipitating Fe as iron sulfides. The result of an increase or decrease in the $\mathrm{dFe}$ efflux would be enhanced or reduced primary productivity by phytoplankton, respectively. Thus, sedimentary iron oxide formation by Zetaproteobacteria may have a direct impact on important water column processes such as carbon fixation. Lithoautotrophic Zetaproteobacteria also contribute directly to dark carbon fixation in sediments, and may provide important organic substrates for heterotrophic microorganisms. The ironcycling microbial communities in combination with ecosystem engineering macrofauna [40] in coastal sediments likely act in concert to recharge riverine iron oxides by intense redox recycling and result in the formation of an enriched highly reactive pool of biogenic iron oxides [30]. The increase in bioturbation intensity and depth that occurred 400 millions years ago [32] has resulted in an interdependent, ecologically complex interaction with sediment-dwelling microorganisms and burrowing macrofauna that are essential to the modern global biogeochemical cycle of iron.

Acknowledgements This project was funded by a National Science Foundation Biological Oceanography Award number OCE-1459600 (D.E.). Sample collection for the Oregon margin and Gulf of Mexico was funded by National Science Foundation grants OCE-1029889 and OCE-1147407, and written contributions by OCE-1715106 (to J.M.). F.J.R.M. was supported through ERC Grant 306933 under the European Union's Seventh Framework Program. C.S.C was supported by a National Science Foundation Biological Oceanography award (OCE1155290). We appreciate Sarabeth George for field and laboratory assistance, Peter Larsen for marine polychaete and hemichordate identification, Anton Tramper for sampling worm burrow and sediments from Netherlands, Peter Girguis and David Johnston for helpful discussions, Megan Harder for assistance with iron oxide and DNA extractions, and Matthew Wade for logistical support. We appreciate the comments from two anonymous reviewers that greatly improved the quality of the final manuscript.

\section{Compliance with ethical standards}

Conflict of interest The authors declare that they have no conflict of interest.

\section{References}

1. Raiswell R, Canfield DE. The iron biogeochemical cycle past and present. Geochemical Perspectives. 2012;1:1-220.

2. Canfield DE, Thamdrup B, Hansen JW. The anaerobic degradation of organic matter in Danish coastal sediments: Iron reduction, manganese reduction, and sulfate reduction. Geochim Cosmochim Acta. 1993;57:3867-83.

3. Aller RC. The Effects of Macrobenthos on Chemical Properties of Marine Sediment and Overlying Water. In: McCall PL, Tevesz MJS, editors. Animal-sediment relations: the biogenic alteration of sediments. Boston, MA: Springer US; 1982. p. 53-102.

4. Canfield DE. Reactive iron in maine sediments. Geochim Cosmochim Acta. 1989;53:619-32.
5. Kristensen E, Kostka JE. Macrofaunal burrows and irrigation in marine sediment: microbiological and biogeochemical interactions. In: Kristensen E, editor. Interactions between macromicroorganisms in marine sediments. Washington, DC: American Geophysical Union; 2005. p. 125-57.

6. Bertics VJ, Ziebis E. Biodiversity of benthic microbial communities in bioturbated coastal sediments is controlled by geochemical microniches. ISME J. 2009;3:1269-85.

7. Emerson D, Fleming EJ, McBeth JM. Iron-oxidizing bacteria: an environmental and genomic perspective. Annu Rev Microbiol. 2010;64:561-83.

8. de Chanvalon AT, Metzger E, Mouret A, Knoery J, Geslin E, Meysman FJR. Two dimensional mapping of iron release in marine sediments at submillimetre scale. Mar Chem. 2017;191:34-49.

9. van de Velde S, Meysman FJR. The influence of bioturbation on iron and sulphur cycling in marine sediments: a model analysis. Aquat Geochem. 2016;22:469-504.

10. McAllister SM, Davis RE, McBeth JM, Tebo BM, Emerson D, Moyer CL. Biodiversity and emerging biogeography of the neutrophilic iron-oxidizing Zetaproteobacteria. Appl Environ Microbiol. 2011;77:5445-57.

11. McBeth JM, Fleming EJ, Emerson D. The transition from freshwater to marine iron-oxidizing bacterial lineages along a salinity gradient on the Sheepscot River, Maine, USA. Environ Microbiol Rep. 2013;5:453-63.

12. Scott JJ, Breier JA, Luther GW, Emerson D. Microbial iron mats at the mid-atlantic ridge and evidence that Zetaproteobacteria may be restricted to iron-oxidizing marine systems. PLoS ONE. 2015;10:1-19.

13. Scott JJ, Glazer BT, Emerson D. Bringing microbial diversity into focus: high-resolution analysis of iron mats from the Lō'ihi Seamount. Environ Microbiol. 2017;19:301-16.

14. Emerson D. The irony of iron-biogenic iron oxides as an iron source to the ocean. Front Microbiol. 2016;6:1-6.

15. Rubin-Blum M, Antler G, Tsadok R, Shemesh E, Austin JA, Coleman DF, et al. First evidence for the presence of iron oxidizing zetaproteobacteria at the levantine continental margins. PLoS ONE. 2014;9:1-10.

16. McAllister SM, Barnett JM, Heiss JW, Findlay AJ, MacDonald DJ, Dow CL, et al. Dynamic hydrologic and biogeochemical processes drive microbially enhanced iron and sulfur cycling within the intertidal mixing zone of a beach aquifer. Limnol Oceanogr. 2015;60:329-45.

17. Laufer K, Nordhoff M, Schmidt C, Behrens S, Jørgensen BB, Kappler A. Co-existence of microaerophilic, nitrate-reducing, and phototrophic $\mathrm{Fe}(\mathrm{II})$-oxidizers and $\mathrm{Fe}(\mathrm{III})$-reducers in coastal marine sediment. Appl Environ Microbiol. 2016;82:1433-47.

18. Reyes C, Dellwig O, Dahnke K, Gehre M, Noriega-Ortega BE, Bottcher ME, et al. Bacterial communities potentially involved in iron-cycling in Baltic Sea and North Sea sediments revealed by pyrosequencing. FEMS Microbiol Ecol. 2016;92:fiw054

19. Field EK, Sczyrba A, Lyman AE, Harris CC, Woyke T, Stepanauskas $\mathrm{R}$, et al. Genomic insights into the uncultivated marine Zetaproteobacteria at Loihi Seamount. ISME J. 2015;9:857-70.

20. Barco RA, Emerson D, Sylvan JB, Orcutt BN, Jacobson Meyers ME, Ramírez GA, et al. New insight into microbial iron oxidation as revealed by the proteomic profile of an obligate iron-oxidizing chemolithoautotroph. Appl Environ Microbiol. 2015;81:5927-37.

21. Barco RA, Hoffman CL, Ramírez GA, Toner BM, Edwards KJ, Sylvan JB. In-situ incubation of iron-sulfur minerals reveals a divese chemolithoautotrophic community and a new biogeochemical role for Thiomicrospira. Environ Microbiol. 2017;19:1322-37.

22. Glud RN. Oxygen dynamics of marine sediments. Mar Biol Res. 2008;4:243-89. 
23. Poulton SW, Canfield DE. Development of a sequential extraction procedure for iron: Implications for iron partitioning in continentally derived particulates. Chem Geol. 2005;214:209-21.

24. Severmann S, McManus J, Berelson WM, Hammond DE. The continental shelf benthic iron flux and its isotope composition. Geochim Cosmochim Acta. 2010;74:3984-4004.

25. Berner RA. Sedimentary pyrite formation: an update. Geochim Coschim Acta. 1984;48:605-15.

26. Lalonde K, Mucci A, Ouellet A, Gelinas Y. Preservation of organic matter in sediments promoted by iron. Nature. 2012;483:198-200.

27. Seitaj D, Schauer R, Sulu-Gambari F, Hidalgo-Martinez S, Malkin SY, Burdorf LDW, et al. Cable bacteria generate a firewall against euxinia in seasonally hypoxic basins. Proc Natl Acad Sci USA. 2015;112:13278-83.

28. Jørgensen BB. Mineralization of organic matter in the sea bedthe role of sulphate reduction. Nature. 1982;296:634-5.

29. Chan CS, Fakra SC, Emerson D, Fleming EJ, Edwards KJ. Lithotrophic iron-oxidizing bacteria produce organic stalks to control mineral growth: implications for biosignature formation. ISME J. 2011;5:717-27.

30. Picard A, Kappler A, Schmid G, Quaroni L, Obst M. Experimental diagenesis of organo-mineral structures formed by microaerophilic $\mathrm{Fe}(\mathrm{II})$-oxidizing bacteria. Nat Commun. 2015;6:6277.

31. Mori JF, Scott JJ, Hager KW, Moyer CL, Küsel K, Emerson D. Physiological and ecological implications of an iron- and hydrogen-oxidizing member of the Zetaproteobacteria, Ghiorsea bivora, gen. nov. sp. nov. ISME J. 2017;11:2624-36.

32. Boudreau BP. Mean mixed depth of sediments: the wherefore and the why. Limnol Oceanogr. 1998;43:524-6.

33. Kallmeyer J, Pockalny R, Adhikari RR, Smith DC, D'Hondt S. Global distribution of microbial abundance and biomass in subseafloor sediment. Proc Natl Acad Sci USA. 2012;109:16213-6.

34. Teal LR, Bulling MT, Parker ER, Solan M. Global patterns of bioturbation intensity and mixed depth of marine soft sediments. Aquat Biol. 2008;2:207-18.

35. Emerson D, Scott JJ, Leavitt AH, Fleming E, Moyer CL. In situ estimates of iron-oxidation and accretion rates for iron-oxidizing bacterial mats at Loihi Seamount. Deep Sea Research Part I. 2017;126:31-19.

36. LaRowe DE, Burwicz E, Arndt S, Dale AW, Amend JP, (2017) Temperature and volume of global marine sediments. Geology 45:275-278

37. Poulton SW, Raiswell R. The low-temperature geochemical cycle of iron: from continental fluxes to marine sediment deposition. Am J Sci. 2002;302:774-805.

38. Lynch MDJ, Neufeld JD, Ecology and exploration of the rare biosphere. Nat Rev Microbiol. 2015;13:217-29.

39. Meysman FJR, Middelburg JJ, Heip CHR. Bioturbation: a fresh look at Darwin's last idea. Trends Ecol Evol. 2006;21:688-95.

40. Tarhan LG, Droser ML, Planavsky NJ, Johnston DT. Protracted development of bioturbation through the early Palaeozoic era. Nat Geosci. 2015;8:865-9. 